\title{
A Methodological Approach to Determine Flower Bud Vulnerability to Low Temperatures for Deciduous Crops in Early Spring Using Degree Days
}

\author{
Andrés Javier Peña Quiñones \\ Washington State University, Prosser, WA
}

\author{
Melba Ruth Salazar Gutierrez \\ Department of Biological Systems Engineering, Washington State University, \\ Prosser, WA
}

\section{Gerrit Hoogenboom}

Institute for Sustainable Food Systems, University of Florida, Gainesville, FL; and Department of Agricultural and Biological Engineering, University of Florida, Gainesville, FL

Additional index words. apple, freezing, frost, sweet cherry, thermal time, uncertainty

\begin{abstract}
A common problem for decision makers in selecting frost control options is uncertainty about the level of injury that can be caused by low temperatures. During the past few years, the concept of lethal temperature (LT) at which $10 \%$ of the bud population dies $\left(\mathrm{LT}_{10}\right)$ has been used as an index for evaluating the vulnerability of flower buds to low temperature conditions. This concept has shown to be a useful tool for frost control decision-making. However, the current methods used to obtain LT values assume no spatial or temporal variability, which results in a high level of uncertainty. The goal of this study was to develop an approach that decreases the uncertainty based on the known effects of temperature on bud vulnerability. A growth chamber experiment was conducted to determine flower bud vulnerability to low temperature as a function of temperature. The results from this study showed that thermal time expressed in degree days could explain changes in floral bud development and vulnerability to frost injury. According to our findings, $L T_{10}$ is a fully acceptable index for determining flower bud vulnerability to low temperatures in orchard crops. Based on this information, we found that among the five apple and cherry cultivars analyzed, 'Gala' is the least vulnerable to low temperature because it starts at the beginning of spring with a high level of hardiness and increases its vulnerability at a low rate. The approach described in this article may enhance decisionmaking certainty associated with the timing and methods to increase air temperature in orchards during low-temperature events to avoid frost damage.
\end{abstract}

Severe weather, especially frost conditions between October and April, can be a significant threat to tree fruit production in temperate zones (Yue et al., 2016). According to Snyder and de Melo-Abreu (2005), the loss of crops due to frost is one of the main weather hazards in the United States, affect-

\footnotetext{
Received for publication 5 Nov. 2019. Accepted for publication $18 \mathrm{Feb} .2020$.

Published online 25 March 2020.

A.J.P.Q. was formerly an AgWeatherNet Program Intern. Current address: Colombian National Center for Sugarcane Research (Cenicaña), Km. 26 vía Cali-Florida, FL, Valle del Cauca, Colombia. M.R.S.G. is an Assistant Research Professor. G.H. is a Preeminent Scholar and Professor. A.J.P.Q. is the corresponding author. E-mail: ajpena@cenicana.org.

This is an open access article distributed under the CC BY-NC-ND license (https://creativecommons. org/licenses/by-nc-nd/4.0/).
}

ing not only fruit production but also regional economies. The most severe losses in deciduous trees are associated with frost events during the flowering season, a period between February and April in the mid latitudes of the Northern Hemisphere (30-50 $)$, known as the de-acclimation stage (Burke et al., 1976; Byrne, 1986; Poling, 2008). During this period, the main concern for growers is to protect the flower primordia from freezing. Orchardists have used various forms of frost protection during the past 2000 years in Europe, Asia, and America (Rodrigo, 2000); however, research is still being conducted on reducing the impact of low temperatures during spring on flower buds in deciduous fruit crops. One of the main accomplishments during the past decades has been the development of the concept of LTs and the determination of LTs for different species and cultivars at different de-acclimation stages (Aslamarz et al., 2010; Caprio and Quamme,
2006; Lindstrom et al., 1995; Mathers, 2004). LT describes the ability of the bud to resist low temperatures (a stress factor), which is the same concept used by Fraser et al. (2013) to define vulnerability. $\mathrm{LT}_{10}, \mathrm{LT}_{50}$, and $\mathrm{LT}_{90}$ represent the low air temperature at which $10 \%, 50 \%$, and $90 \%$ of the flower buds are killed (Salazar-Gutierréz et al., 2014, 2016). During the past 20 years, LT has been used as index for evaluating the vulnerability of flower buds to low temperatures and LT is currently the basis for frost control decisionmaking (Rodrigo, 2000).

Exposure, a concept also used in riskhazard analyses, describes whether a threat event is likely to damage a system or entity (Fraser et al., 2013; Jedryczka et al., 2015; Turner et al., 2003). The outcome of such an analysis is to select the cultivars or species with the lowest vulnerability to the coldest sites according to the Agricultural Research Service, U.S. Department of Agriculture (2012). However, active methods for frost protection that are used to decrease the lowtemperature threats after sowing or planting (e.g., Perry, 1998; Poling, 2008) require highenergy investments (Cary, 1974). For example, to reduce the injury probability on a radiation frost night through an increase in the surface air temperature requires between 10 and $50 \mathrm{~W} \cdot \mathrm{m}^{-2}$ of energy input (Snyder and de Melo-Abreu, 2005). Depending on the efficiency of the method that is being used, such as heaters, wind machines, and irrigation devices, the energy investment could even be higher. There is, therefore, a need for increasing frost control effectiveness by only using devices when they are needed, thereby avoiding the two most common problems: 1 ) using frost protection devices when they are not needed, and 2) keeping devices off when they should be turned on. Optimal use of frost control devices could avoid such scenarios that occur when growers take risks due to a lack of sufficient information and uncertainty about whether predicted air temperatures will cause injury (Kappel, 2010). Because of the temporal variability in cold hardiness, extremely low temperatures can occur during certain periods of the season without consequences to the flower buds, whereas moderately low temperatures can occur during critical periods and have a significant impact on final yield (Burke et al., 1976).

As stated previously, LT of the flower buds is an index of vulnerability that is currently being used as a trigger for frost control decisions to avoid the two error scenarios described previously. However, despite the importance of LT, the temperature values are normally inferred by using approaches that assume the air temperature is constant for an entire region. One common methodology currently used measures the LT at a research location and disseminates the results to growers. Another approach assumes that each growth stage has its own LT (Ballard, 1978; Ballard et al., 1997). The first method implies that LT does not have spatial variability, whereas the second assumes that this value is not variable over 
different growing seasons. These two methods imply that all buds are in in the same growth stage. The goal of this study was to develop a method for solving the assumption of fixedness associated with flower bud development stages by using the thermal time concept to relate the air temperature to the $\mathrm{LT}$.

\section{Materials and Methods}

\section{Field samples}

Three sweet cherry cultivars (Prunus avium L.), Bing, Chelan, and Sweet Heart, and two apple cultivars (Malus domestica Borkh.), Gala and Red Delicious, were sampled in 2013 and 2014 from orchards located at the Roza Farm of the Irrigated Agriculture Research and Extension Center of Washington State University in Prosser, WA (lat. $46.29^{\circ} \mathrm{N}$, long. $119.73^{\circ} \mathrm{W}, 359.70$ masl). While the buds were dormant and before the bud swelling stage, samples of tree branch segments ranging from $0.35 \mathrm{~m}$ to $0.50 \mathrm{~m}$ in length were collected in the field. One week after the weekly mean temperature reached $0{ }^{\circ} \mathrm{C}$ (first week of Feb. 2013 and last week of Feb. 2014), a total of 105 twigs for each cultivar had been obtained.

\section{Laboratory}

For both years, the total of 105 twig segments were split into three groups with three subsets of 35 twig segments for each cultivar. The twigs were placed in 15 buckets ( 3 subsets $\times 5$ cultivars) of $0.03 \mathrm{~m}^{3}$ containing $0.0025 \mathrm{~m}^{3}$ of surface water. For apples, each twig had $\approx 15$ buds $(15.2 \pm 1.3)$, and for cherries each twig had $\approx 60$ buds. Samples were exposed to three temperature treatments in growth chambers (Conviron, Winnipeg, Canada) programmed to simulate different types of spring days with low, medium, and high temperatures at a photoperiod of $14 \mathrm{~h}$ (Fig. 1). The relative humidity in each chamber was kept constant at $70 \%$. A total of five buckets were placed in each chamber. LT was measured at least once per week, starting on the day when the samples were collected (Table 1). From each chamber, 200 floral buds of each sweet cherry cultivar and 70 floral buds of each apple cultivar were randomly removed from the branches for each sampling date. Ten subsamples were created with 20 flower buds for each sweet cherry cultivar and seven for each apple cultivar to determine the LTs using the methodology described by Salazar-Gutierréz et al. (2014), referred to as the "vending machine." This methodology involves the use of a temperature test chamber (Model T2; Tenney, White Deer, PA) for simulating frost and freeze events. The temperature chamber holds 10 perforated cylinders in which bud samples are placed and an electronic system removes each cylinder from the chamber depending on the settings. The chamber decreases its internal temperature from 4 to $-44^{\circ} \mathrm{C}$ at a rate of $-4{ }^{\circ} \mathrm{C} \cdot \mathrm{h}^{-1}$ taking into account the air temperature data collected by four precision type "T" thermocouples (Model 5TC-TT-T30-72; Omega, Norwalk, CT) located within

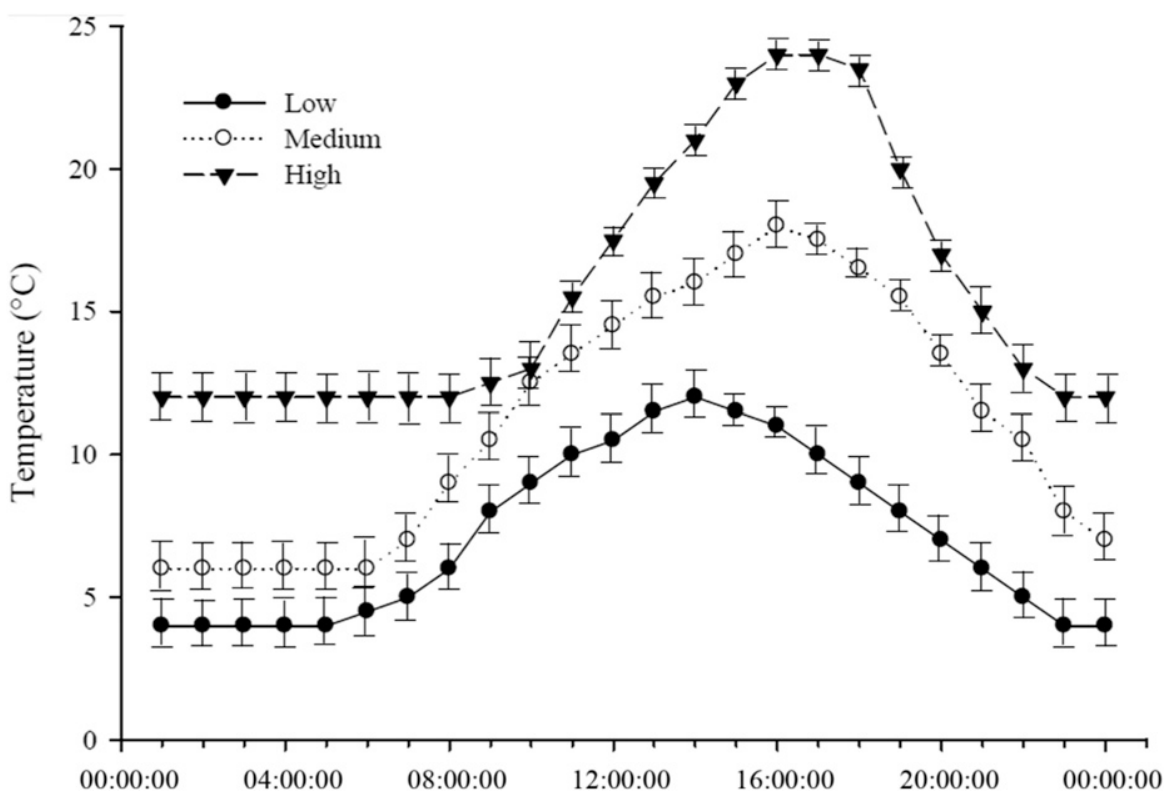

Fig. 1. Hourly temperature set points (markers) and the actual variation in air temperature variation (bars) within the three individual growth chambers.

the chamber. For our experiment, the cylinders were removed from the chamber at 10 fixed temperatures based on previous LT studies (Ballard, 1978; Ballard et al., 1997; Proebsting and Mills, 1978). For example, if $\mathrm{LT}_{10}$ was reported as $-2{ }^{\circ} \mathrm{C}$ and $\mathrm{LT}_{90}$ was reported as $-15^{\circ} \mathrm{C}$ for a specific growth stage, the system was programmed to extract the samples that were placed inside the cans at $2{ }^{\circ} \mathrm{C}$ starting at $0{ }^{\circ} \mathrm{C}$ and ending at $-18{ }^{\circ} \mathrm{C}$. The cans were marked to show the minimum temperature to which the buds were exposed.

After the cold exposure, flower buds were dissected to determine the number of dead buds. The evaluation of dead and live buds was performed according to the method described by Salazar-Gutierréz et al. (2014). This analysis was carried out using a Nikon SMZ-740 Stereo Microscope (Melville, NY). The degree of damage in the buds in each can was calculated as the ratio between the number of dead buds and the total number of buds per can.

\section{Data analysis}

LT determination. $\mathrm{LT}_{10}, \mathrm{LT}_{50}$, and $\mathrm{LT}_{90}$ were obtained using the methodology described by Salazar-Gutierréz et al. (2014). LTn is a generalization of the LTEn, parameter that was defined by Proebsting et al. (1980) based on the analysis of differential thermal analysis. Following frost damage assessment that was described previously, a logistic model was used to relate the cumulative percentage of dead buds to the minimum temperature to which they had been exposed [Eq. (1)]. To estimate the parameters of the logistic model (Lindén et al., 1996), the NLIN procedure (SAS Institute Inc., 2008) was used

$$
y=\frac{A}{1+e^{-K(x-G)}}
$$

where $y$ represents the relationship of the cumulative percentage of dead buds, $A$ is the upper asymptote, $K$ is the "slope-parameter," and $G$ is the inflexion point of the curve. According to Stewart et al. (1984), $\mathrm{LT}_{10}$ has a practical use for farmers as a decision threshold because when the air reaches the value of $\mathrm{LT}_{10}$, an additional small decrease in air temperature could cause significant damage. We, therefore, used it as a vulnerability indicator. To analyze the change in vulnerability over time $\left({ }^{\circ} \mathrm{C} \cdot \mathrm{d}^{-1}\right)$, a simple regression analysis was conducted in which $\mathrm{LT}_{10}$ was the dependent variable and the number of days after the branch segments were placed in the chamber (DAC) was the independent variable.

Degree-day calculation. A similar analysis was conducted using thermal time instead of real time expressed as the number of days. The thermal time, reported as degree days, was calculated for each growth chamber. In this case, each chamber had the same air temperature response during the entire experiment (Fig. 1), and the thermal time accumulation for each day was the same for each individual chamber. Thermal time was calculated by using the rectangle method (midpoint approximation) of integration [Eq. (2)]

$$
D D=\sum_{n=1}^{24} \frac{\left(T_{i}-T_{b}\right)}{24}
$$

where $D D$ is the degree days, $T_{i}$ is the temperature inside the chamber at each hour (Fig. 1), and $T_{b}$ is the base temperature. We used a $\mathrm{T}_{\mathrm{b}}$ of $4{ }^{\circ} \mathrm{C}$ based on earlier reports for Prunus species and apples (Citadin et al., 2001; Hochmaier, 2014; Usenik and Stampar, 2011; Zavalloni et al., 2006). Using Eq. [2], a total of 11.77-degree days are accumulated per day for the chamber simulating a high temperature, 6.76-degree days for the chamber simulating a medium temperature, 


\begin{tabular}{|c|c|c|c|c|c|c|c|c|c|c|}
\hline \multirow[b]{2}{*}{$\mathrm{Yr}$} & \multicolumn{2}{|c|}{ Gala } & \multicolumn{2}{|c|}{ Red Delicious } & \multicolumn{2}{|c|}{ Bing } & \multicolumn{2}{|c|}{ Chelan } & \multicolumn{2}{|c|}{ Sweet Heart } \\
\hline & Date & DAC & Date & $\overline{\mathrm{DAC}}$ & Date & $\mathrm{DAC}$ & Date & $\overline{\mathrm{DAC}}$ & Date & $\mathrm{DAC}$ \\
\hline \multirow[t]{5}{*}{2013} & 18 Feb. & 3 & 18 Feb. & 3 & $21 \mathrm{Feb}$ & 0 & 19 Feb. & 0 & 19 Feb. & 0 \\
\hline & 25 Feb. & 10 & 25 Feb. & 10 & 25 Feb. & 4 & 27 Feb. & 8 & 27 Feb. & 8 \\
\hline & 1 Mar. & 14 & 1 Mar. & 14 & 4 Mar. & 11 & 4 Mar. & 11 & 1 Mar. & 10 \\
\hline & & & & & 11 Mar. & 17 & 18 Mar. & 27 & 11 Mar. & 21 \\
\hline & & & & & 18 Mar. & 24 & 25 Mar. & 34 & & \\
\hline \multirow[t]{9}{*}{2014} & 3 Mar. & 0 & 3 Mar. & 0 & 3 Mar. & 0 & 3 Mar. & 0 & 3 Mar. & 0 \\
\hline & 8 Mar. & 5 & 5 Mar. & 2 & 5 Mar. & 2 & 4 Mar. & 1 & 10 Mar. & 7 \\
\hline & 10 Mar. & 7 & 10 Mar. & 7 & 6 Mar. & 3 & 8 Mar. & 5 & 13 Mar. & 10 \\
\hline & 15 Mar. & 12 & 12 Mar. & 9 & 13 Mar. & 10 & 10 Mar. & 7 & 20 Mar. & 17 \\
\hline & 19 Mar. & 16 & 19 Mar. & 16 & 17 Mar. & 14 & 17 Mar. & 14 & 24 Mar. & 21 \\
\hline & 26 Mar. & 23 & 25 Mar. & 22 & 24 Mar. & 21 & 20 Mar. & 17 & 26 Mar. & 23 \\
\hline & 1 Apr. & 29 & 3 Apr. & 31 & 2 Apr. & 30 & 23 Mar. & 20 & 2 Apr. & 30 \\
\hline & & & & & 14 Apr. & 42 & 2 Apr. & 30 & 14 Apr. & 42 \\
\hline & & & & & & & 14 Apr. & 42 & & \\
\hline
\end{tabular}

and 3.76-degree days for the chamber simulating a low temperature or cold day.

\section{Results}

General observations. Our research showed that flower buds that were exposed to high temperatures had a faster development rate than flower buds exposed to low temperatures (Fig. 2). Our results also confirmed the effect of temperature on flowering dates. However, we did not find a relation between the minimum air temperature that was reached during the winter and budbreak and flower development. We found that the three cherry cultivars used during our study, i.e., Bing, Chelan, and Sweet Heart, were more sensitive to temperature changes than the two apple cultivars, i.e., Red Delicious and Gala. For the simulated cold spring days, the five cultivars had similar bud development rates of $\approx 8$ to $10 \mathrm{~d}$ per stage. However, when the flower buds were exposed to warmer conditions, the developmental rate increased; the cherry buds flowered five times faster and the apple buds flowered two times faster compared with the flower buds exposed to low temperatures. (Fig. 2).

Cold vulnerability assessment. We found that warm spring days and nights can increase the susceptibility of flower buds to low temperatures (Table 2). In our experiment, the cherry and apple cultivars responded in different ways to the temperature treatments: under high and medium temperatures, flower buds of 'Sweet Heart' (cherry) and 'Red Delicious' (apple) exhibited a more rapid increase in vulnerability compared with the other cultivars evaluated (Table 2). This finding means that during spring, the presence of daily maximum temperatures above $14{ }^{\circ} \mathrm{C}$ can decrease the cold hardiness of flower buds at $\approx 0.25{ }^{\circ} \mathrm{C}$, a value that is greater for 'Sweet Heart' and 'Red Delicious' ( 0.39 and 0.27 , respectively). On the other hand, on days when the maximum temperature is below $10{ }^{\circ} \mathrm{C}$, the vulnerability of flower buds to cold conditions increased at a flat rate for all cultivars and showed that the cherry cultivars were hardier than apple varieties.

The results suggest that the worst scenario is a freezing night after warm days. High temperatures during warm days not only

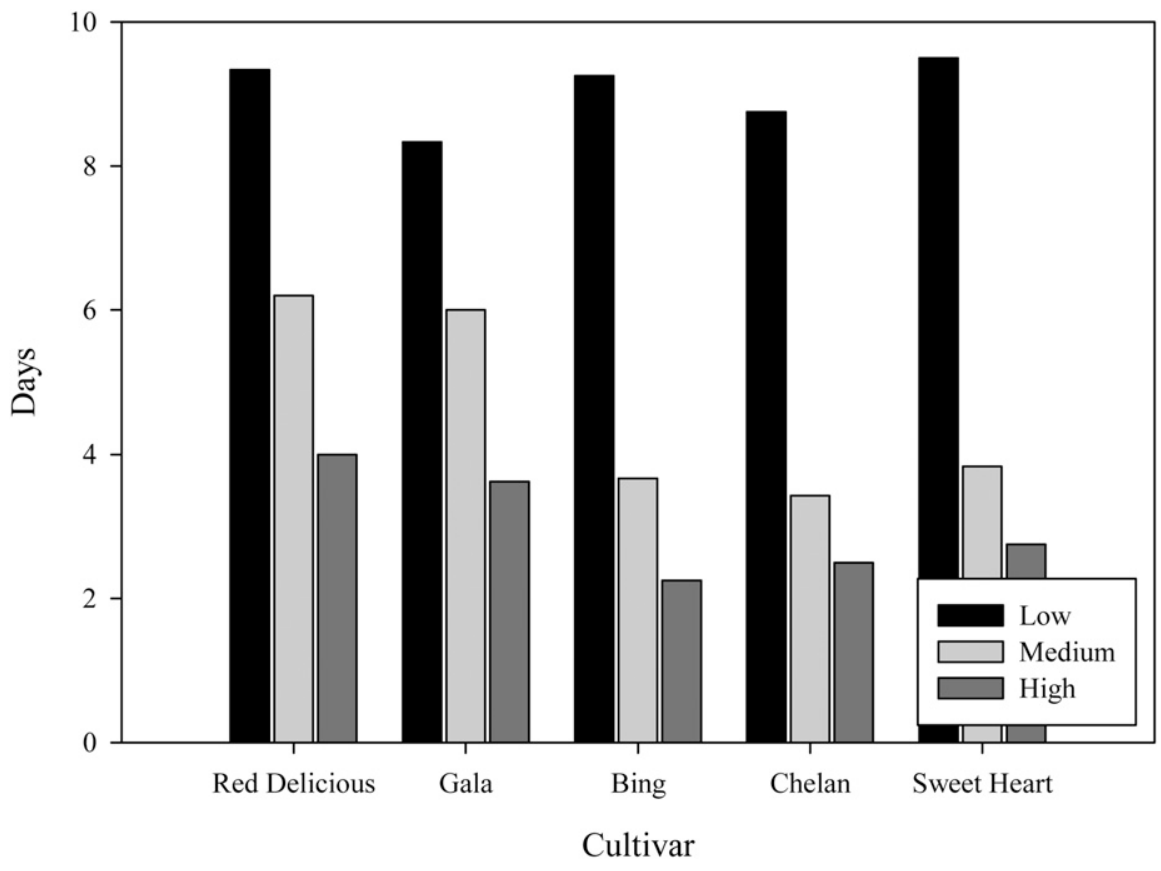

Fig. 2. Flower bud development of apples ('Red Delicious' and 'Gala') and cherries ('Bing', 'Chelan', and 'Sweet Heart') within the growth chambers (low, medium, and high temperature) expressed as the average number of days to complete each growth stage, according to the stages reported by Ballard et al. (1997) and Ballard (1978).

increase the rate of bud development but also increase bud vulnerability (Fig. 3). The increase in flower bud vulnerability is highly correlated with thermal accumulation (Fig. 3). The linear regression that relates degree day and vulnerability shows a similar slope for the apple cultivar Red Delicious $\left(0.020{ }^{\circ} \mathrm{C}\right.$ per degree day) and the cherry varieties, 'Bing' (0.022 ${ }^{\circ} \mathrm{C}$ per degree day), 'Chelan' $\left(0.017^{\circ} \mathrm{C}\right.$ per degree day), and 'Sweet Heart' $\left(0.020{ }^{\circ} \mathrm{C}\right.$ per degree day). The apple cultivar Gala is less vulnerable than the other cultivars, and its vulnerability increases at $0.01{ }^{\circ} \mathrm{C}$ per degree day. The intercept of the adjusted linear model is close to $-8{ }^{\circ} \mathrm{C}$ for apple and approximately $-6^{\circ} \mathrm{C}$ for sweet cherries. The intercept shows that at the beginning of the spring season before bud burst, apple buds are less vulnerable to cold environments than sweet cherry buds (Fig. 3). This finding explains why despite the increase in vulnerability rate, 'Red
Delicious' is more hardy than cherry cultivars. These findings concur with those reported by Snyder and de Melo-Abreu (2005), showing apples are less vulnerable to cold before bud burst than sweet cherries.

\section{Discussion}

The effect of air temperature on the flower bud development has been reported in several studies. Roetzer et al. (2000) found that in the same region, apple and cherry trees planted in urban areas, characterized by warmer conditions, flowered earlier than the ones planted in rural areas. Usenik and Stampar (2011) stated that a small and nonsignificant change in air temperature can generate an important variability in the number of days between bloom and maturity for sweet cherries. Therefore, some authors have suggested using the full bloom dates for cherries 
Table 2. Vulnerability rate $\left({ }^{\circ} \mathrm{C} \cdot \mathrm{d}^{-1}\right)$ as function of the air temperature within the growth chamber: High, Medium, and Low as appear in Fig. 1. Vulnerability expressed as increase of lethal temperature (loss of cold hardiness) per day (slope, ${ }^{\circ} \mathrm{C} \cdot \mathrm{d}^{-1}$ ).

\begin{tabular}{|c|c|c|c|c|c|c|c|c|c|c|}
\hline & \multirow{2}{*}{ Cultivar } & \multicolumn{9}{|c|}{ Growth chamber } \\
\hline & & \multicolumn{3}{|c|}{ High } & \multicolumn{3}{|c|}{ Medium } & \multicolumn{3}{|c|}{ Low } \\
\hline Apple & Gala & 0.31 & 0.72 & 0.03 & 0.22 & 0.52 & 0.09 & 0.15 & 0.42 & 0.11 \\
\hline \multirow[t]{3}{*}{ Cherry } & Bing & 0.29 & 0.99 & 0.00 & 0.18 & 0.89 & 0.00 & 0.05 & 0.79 & 0.00 \\
\hline & Chelan & 0.32 & 0.81 & 0.00 & 0.14 & 0.38 & 0.15 & 0.07 & 0.30 & 0.12 \\
\hline & Sweet Heart & 0.44 & 0.88 & 0.00 & 0.39 & 0.79 & 0.02 & 0.05 & 0.13 & 0.42 \\
\hline
\end{tabular}
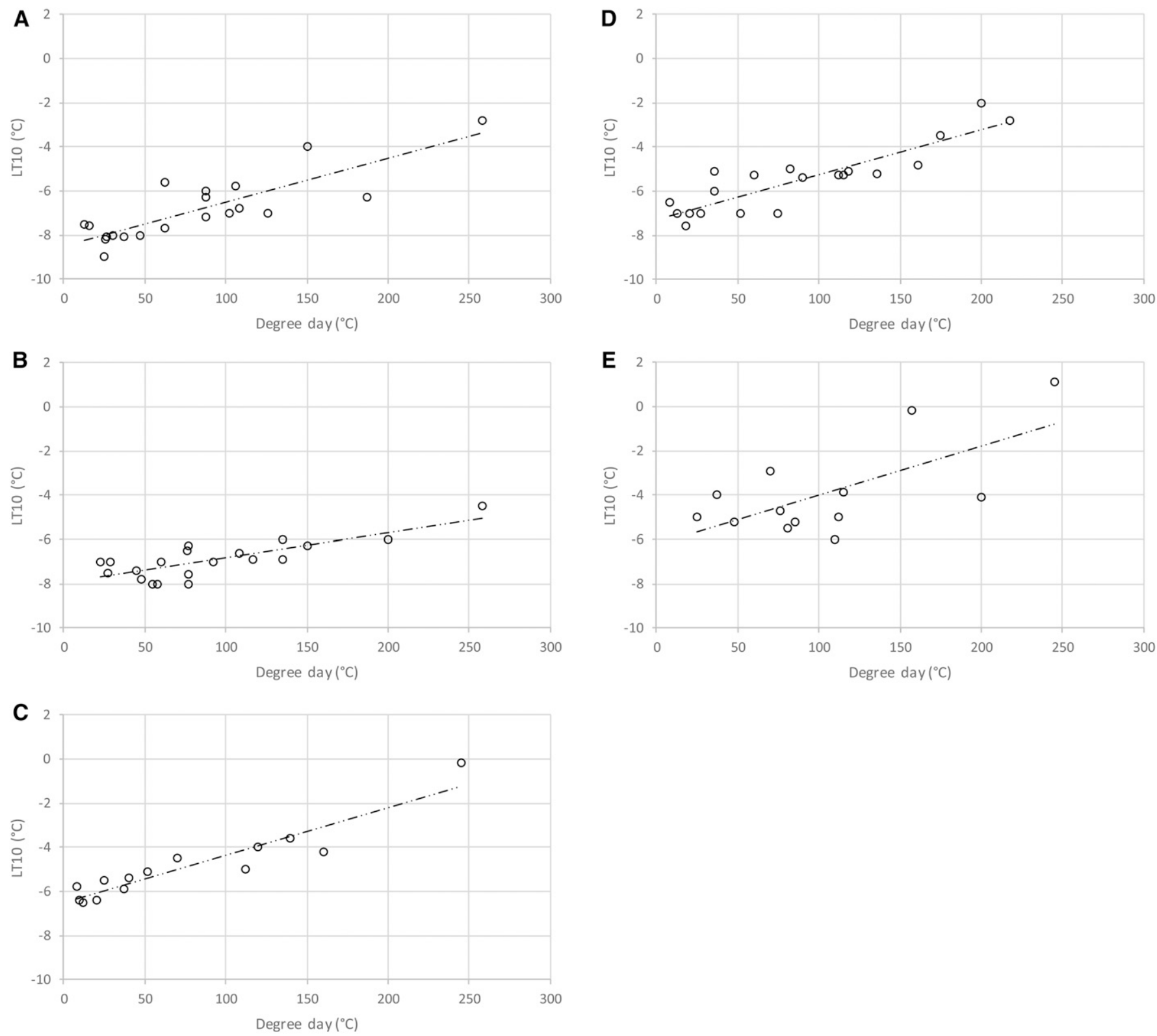

Fig. 3. Vulnerability to cold injury, determined as the temperature that causes $10 \%$ damage in a bud population $\left(\mathrm{LT}_{10}\right)$, as a function of accumulated degree days for the apple cultivars Red Delicious (A) Gala (B) and the cherry cultivars Bing (C), Chelan (D), and Sweet Heart (E).

registered around the world during the past century for reconstructing long-term air temperature records, or at least for identifying colder and warmer years (Aono and Kazui, 2008; Cleland et al., 2007; Elzinga et al., 2007; Linderholm, 2006). In our study, we did not find the effect of the winter minimum air temperature on the budbreak and flower development, which has been reported by Takeda et al. (2002). During the winter, apple trees store carbohydrates predominantly in the root zone, and reallocation of carbohydrates is required for budbreak. Greer et al. (2005) found that an increase in soil temperature affected budbreak and the rate of floral cluster opening. The soil tem- perature during the early spring is affected by the air temperature of the prior winter period because of the buffering capacity of the soil. However, for apple and sweet cherry cultivars with deep root systems, the soil moisture before the start of the winter can have a larger effect compared with temperature. 

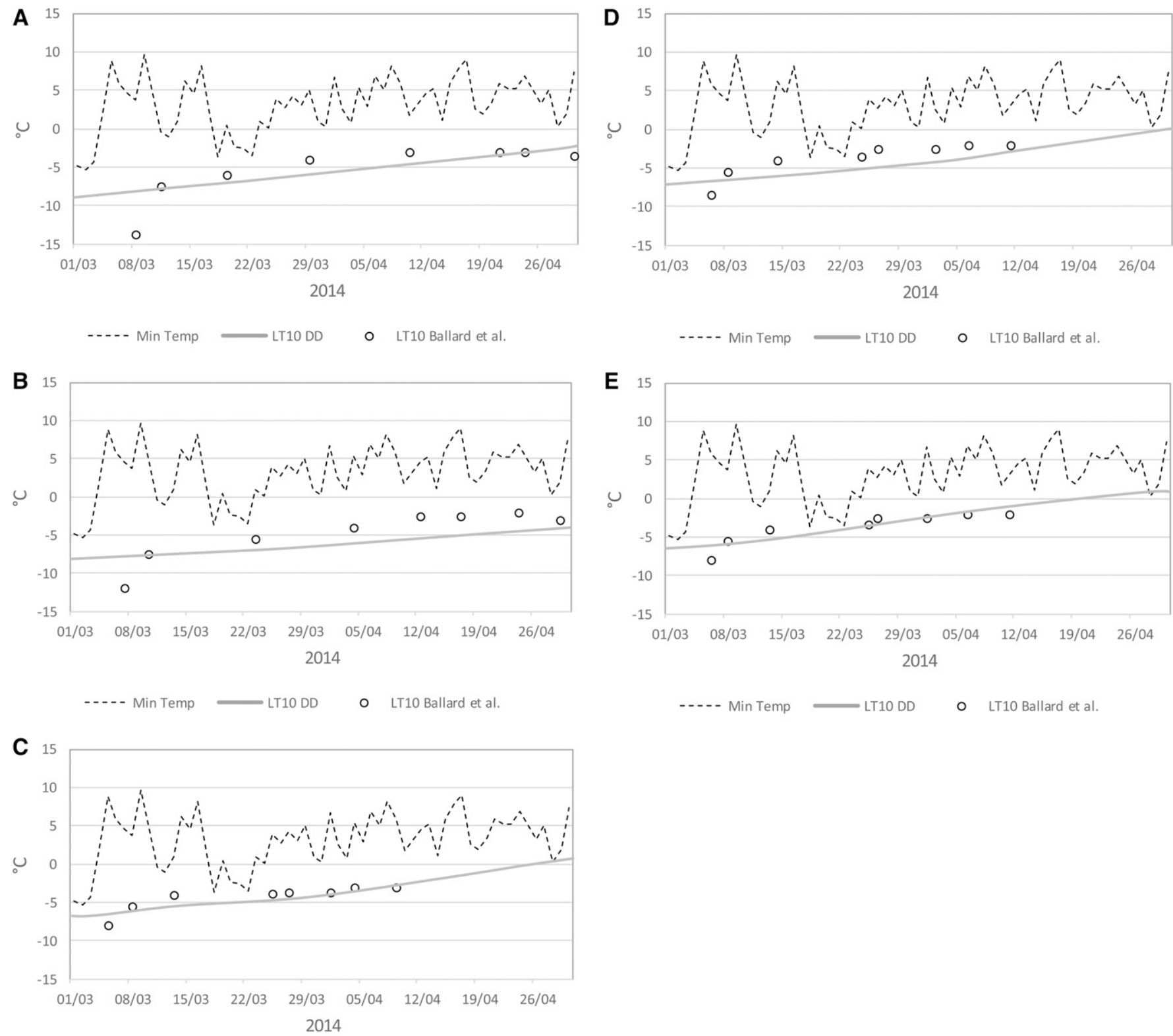

- - - Min Temp LT10 DD O LT10 Ballard et al. I

Fig. 4. Comparison between two ways for vulnerability determination, the method based on the degree-day's accumulation [lethal temperature at which $10 \%$ of the bud population dies $\left.\left(\mathrm{LT}_{10}\right) \mathrm{DD}\right]$ and the approach based on the growing stage [LT 10 , Ballard et al. (1997)]. Phenological observations are from Roza Farm (Winter-Spring 2014) and vulnerability computed by using daily weather data from the Roza weather station for apples, 'Red Delicious' (A) and 'Gala' (B), and cherries, 'Bing' (C), 'Chelan' (D), and 'Sweet Heart' (E).

Cold vulnerability assessment. Susceptibility of flower buds to low temperatures increased when the bud development is faster for higher temperatures, which is similar to the results reported by Proebsting and Mills (1978) and Salazar-Gutierréz et al. (2014). Although other studies have found the same effect, the primary focus was the dependency of cold hardiness during the development stage of the buds. To avoid the use of the developmental stage as a reference for decision-making, our approach considered using degree days. The use of the developmental stage as a trigger for a decision could be a restrictive approach. This restriction is associated with the high variability of flower bud stages that are present on the same shoot on a specific day, as discussed by Zavalloni et al. (2006). The methodology that we followed considers all the flower stages present on the shoots, and, therefore, by using the thermal time concept we not only considered the effect of air temperature on the flower bud development (e.g., Aono and Kazui, 2008; Greer et al., 2005; Guillaume et al., 2017; Hassankhah et al., 2017), but also the effect of air temperature on the soil temperature. As previously mentioned, soil temperature is related to the reduction in soluble sugar content, such as sucrose, raffinose, and stachyose, and is associated with flower development that affects the loss of cold hardiness (Greer et al., 2005).

After using the degree days approach, our findings concur with tree sellers' criteria for apple and sweet cherry variety recommendation. This recommendation is based on the U.S. Department of Agriculture Plant Hardiness Zone Map (Agricultural Research Service, U.S. Department of Agriculture, 2012). According to this map, zones 4, 5, 6, and 7 are predominate in the Pacific Northwest. Nurseries recommend planting 'Gala' in colder locations (Zone 4) compared with warmer zones where they recommend planting 'Red Delicious' (Zone 5), an indication that 'Gala' is less vulnerable to cold conditions. In the case of sweet cherries, nurseries do not recommend 'Sweet Heart' for zones with warmer winters. Although 'Bing' and 'Chelan' are recommended for zones 5 to 9, 'Sweet Heart' is recommended only for zones 5 to 7 , 
demonstrating the requirements for colder conditions for 'Sweet Heart' but at the same time its susceptibility to warmer environments.

A comparison of the $\mathrm{LT}_{10}$ computed using the approach commonly used by growers, which relies on the evaluation of the growth stage in the field, and the LT for each flower bud stage (Ballard et al., 1997) to provide growers with the degree of vulnerability, and our approach, based on degree days, was performed with data collected during Spring 2014. Our method took into consideration the thermal time calculation of air temperature data recorded at the weather station located on the Roza Farm, starting with the accumulation on 1 Mar. 2014. The growth stage was determined for five cultivars, including Red Delicious, Gala, Bing, Chelan, and Sweet Heart, planted in orchards on the Roza Farm. The results showed that there was no significant difference between the $\mathrm{LT}_{10}$ generated with our approach and the approach suggested by Ballard et al. (1997) (Fig. 4). $\mathrm{LT}_{10}$, the temperature at which $10 \%$ of the buds are killed during a frost night, is considered an adequate vulnerability index to meet an exposure approach and to make decisions about freeze control for an orchard. The differences in vulnerability depend on the response of the air temperature and degree day accumulation. Warm spring days not only increase flower development, as has previously been reported (Camargo et al., 2019; Caprio and Quamme, 2006; Usenik and Stampar, 2011; Zapata et al., 2015), but also increase the vulnerability of the flower buds to low temperatures. There was a noticeable correlation between the bud's developmental stage and its vulnerability. Our results also showed that flower buds of apples were less vulnerable to cold nights than flower buds of sweet cherry; however, the rate of increase of vulnerability was the same for almost all cultivars at $\approx 0.02{ }^{\circ} \mathrm{C}$ per degree day. The least vulnerable variety was 'Gala', which increases its vulnerability at a lower rate of $0.01{ }^{\circ} \mathrm{C}$ per degree day compared with the other cultivars. The vulnerability for the remainder of the season can be calculated by determining the $\mathrm{LT}_{10}$ before budburst and the degree days accumulated during the period preceding to budburst. This can then reduce the uncertainty that is faced by growers with respect to deciding whether to turn on freeze protection devices to increase the air temperature in the orchard. The current study did not consider bud position, which could be important for future research, as shown by Aslamarz et al. (2009).

\section{Conclusion}

$\mathrm{LT}_{10}$ is a fully acceptable index for determining flower bud vulnerability to low temperatures in orchard crops. There is an important correlation between the thermal time accumulated during early spring and the vulnerability of flower buds to low temperatures. The approach described in this study identified the differences among vari- eties, determining that the rate of increase in vulnerability of 'Red Delicious' and 'Sweet Heart' is greater than for other cultivars. In addition, the approach reported in this study found a more precise methodology to detect vulnerability compared with the current methods that are being used for making frost protection decisions.

\section{Literature Cited}

Agricultural Research Service, U.S. Department of Agriculture. 2012. USDA Plant Hardiness Zone Map. 17 Dec. 2018. <http://planthardiness.ars.usda.gov>.

Aono, Y. and K. Kazui. 2008. Phenological data series of cherry tree flowering in Kyoto, Japan, and its application to reconstruction of springtime temperatures since the 9th century. Intl. J. Climatol. 28:905-914.

Aslamarz, A.A., K. Vahdati, M. Rahemi, and D. Hassani. 2009. Estimation of chilling and heat requirements of some persian walnut cultivars and genotypes. HortScience 44:697-701.

Aslamarz, A.A., K. Vahdati, M. Rahemi, D. Hassani, and C. Leslie. 2010. Supercooling and coldhardiness of acclimated and deacclimated buds and stems of persian walnut cultivars and selections. HortScience 45:1662-1667.

Ballard, J.K. 1978. Frost and frost control in Washington orchards. Washington State University, Cooperative Extension Service, Pullman, WA.

Ballard, J.K., E.L. Proebsting, and R.B. Tukey. 1997. Critical temperatures for blossom buds, cherries. Washington State University, Pullman, WA.

Burke, M.J., L. Gusta, H.A. Quamme, C.J. Weisser, and P.H. Li. 1976. Freezing and injury in plants. Annu. Rev. Plant Physiol. 27:507-528.

Byrne, D.H. 1986. Mechanisms of spring freeze injury avoidance in peach. HortScience 15:1235-1236.

Camargo-Alvarez, H., M. Salazar, M. Keller, and G. Hoogenboom. 2020. Modeling the effect of temperature on bud dormancy of grapevines. Agr. For. Meteorol. 280:107782.

Caprio, J.M. and H.A. Quamme. 2006. Influence of weather on apricot, peach and sweet cherry production in the Okanagan Valley of British Columbia. Can. J. Plant Sci. 86:259-267.

Cary, J.W. 1974. An energy-conserving system for orchard cold protection. Agr. Meteorol. 13:339-348.

Citadin, I., M. Raseira, F. Herter, and B. Baptista da Silva. 2001. Heat requirement for blooming and leafing in peach. HortScience 36:305-307.

Cleland, E.E., I. Chuine, M. Annette, H.A. Mooney, and M.D. Schwartz. 2007. Shifting plant phenology in response to global change. Trends Ecol. Evol. 22(7):357-365.

Elzinga, J.A., A. Atlan, A. Biere, L. Gigord, A.E. Weis, and G. Bernasconi. 2007. Time after time: Flowering phenology and biotic interactions. Trends Ecol. Evol. 22(8):432-439.

Fraser, E., E. Simelton, M. Termansen, S. Gosling, and A. South. 2013. "Vulnerability hotspots": Integrating socio-economic and hydrological models to identify where cereal production may decline in the future due to climate change induced drought. Agr. For. Meteorol. 170:195205.

Greer, D.H., J.N. Wunsche, C.L. Norling, and H.N. Wiggins. 2005. Root-zone temperatures affect phenology of bud break, flower cluster development, shoot extension growth and gas exchange of 'Braeburn' (Malus domestica) apple trees. Tree Physiol. 26:105-111.

Guillaume, C., C. Isabelle, B. Marc, and A. Thierry. 2017. Assessing frost damages using dynamic models in walnut trees: Exposure rather than vulnerability controls frost risks. Plant Cell Environ. 41(5):1008-1021.

Hassankhah, A., K. Vahdati, M. Rahemi, D. Hassani, and S. Khorami. 2017. Persian walnut phenology: effect of chilling and heat requirements on budbreak and flowering date. Intl. J. Hort. Sci. Technol. 4(2):259-271.

Hochmaier, V. 2014. Chilling unit accumulation and degree-day requirements of four sweet cherry (Prunus avium L.) cultivars. Acta Hort. 1020:203-207.

Jedryczka, M., A. Strzelczak, A. Grinn-Gofron, M. Nowak, T. Wolski, M. Siwulski, K. Sobieralski, and J. Kaczmarek. 2015. Advanced statistical models commonly applied in aerobiology cannot accurately predict the exposure of people to Ganoderma spore-related allergies. Agr. For. Meteorol. 201:209-217.

Kappel, F. 2010. Sweet cherry cultivars vary in their susceptibility to spring frosts. HortScience 45:176-177.

Lindén, L., H. Rita, and T. Suojala. 1996. Logit models for estimating lethal temperatures in apple. HortScience 31:91-93.

Linderholm, H.W. 2006. Growing season changes in the last century. Agr. For. Meteorol. 137:1-14.

Lindstrom, O.M., T. Anisko, and M.A. Dirr. 1995. Low-temperature exotherms and cold hardiness in three taxa of deciduous trees. J. Amer. Soc. Hort. Sci. 120:830-834.

Mathers, H.M. 2004. Supercooling and cold hardiness in sour cherry germplasm: flower buds. J. Amer. Soc. Hort. Sci. 129:675-681.

Perry, K.B. 1998. Basics of frost and freeze protection for horticultural crops. HortTechnology 8:10-15.

Poling, E.B. 2008. Spring cold injury to winegrapes and protection strategies and methods. HortScience 43:1652-1662.

Proebsting, E.L. and H.H. Mills. 1978. Low temperature resistance of developing flower buds of six deciduous fruit species. J. Amer. Soc. Hort. Sci. 103:192-198.

Proebsting, E.L., M. Ahmedullah, and V.P. Brummund. 1980. Seasonal changes in low temperature resistance of grape buds. Amer. J. Enol. Viticult. 31(4):329-336.

Rodrigo, J. 2000. Spring frosts in deciduous fruit trees-morphological damage and flower hardiness. Scientia Hort. 85(3):155-173.

Roetzer, T., M. Wittenzeller, H. Haeckel, and J. Nekovar. 2000. Phenology in central Europe differences and trends of spring phenophases in urban and rural areas. Intl. J. Biometeorol. 44:60-66.

Salazar-Gutiérrez, M.R., B. Chaves, J. Anothai, M. Whiting, and G. Hoogenboom. 2014. Variation in cold hardiness of sweet cherry flower buds through different phenological stages. Scientia Hort. 172:161-167.

Salazar-Gutiérrez, M.R., B. Chaves, and G. Hoogenboom. 2016. Freezing tolerance of apple flower buds. Scientia Hort. 198:344-351.

SAS Institute Inc. 2008. SAS/STAT® 9.2 User's Guide. SAS Institute Inc., Cary, NC.

Snyder, R.L. and J.P. de Melo-Abreu. 2005. Frost protection: Fundamentals, practice and economics Volume I. Food and Agriculture Organization of the United Nations, Rome.

Stewart, T.R., R.W. Katz, and A.H. Murphy. 1984. Value of weather information: A descriptive study of the fruit-frost problem. Bull. Amer. Meteorol. Soc. 65(2):126-144.

Takeda, F., B.C. Strik, D. Peacock, and J.R. Clark. 2002. Cultivar differences and the effect of winter temperature on flower bud development in blackberry. J. Amer. Soc. Hort. Sci. 127:495-501.

Turner, B.L., R.E. Kasperson, P. Matson, J. McCarthy, R. Corell, L. Christensen, N. Eckley, J.X. 
Kasperson, A. Luers, M.L. Martello, C. Polsky, A. Pulsipher, and A. Schiller. 2003. A framework for vulnerability analysis in sustainability science. Proc. Natl. Acad. Sci. USA 100(14): 8074-8079.

Usenik, V. and F. Stampar. 2011. The effect of environmental temperature on sweet cherry phenology. Eur. J. Hort. Sci. 76(1):1-5.
Yue, Y., Y. Zhou, J. Wang, and X. Ye. 2016. Assessing wheat frost risk with the support of GIS: An approach coupling a growing season meteorological index and a hybrid fuzzy neural network model. Sustainability 8(12): 1308

Zapata, D., M. Salazar, B. Chaves, M. Keller, and G. Hoogenboom. 2015. Estimation of the base temperature and growth phase duration in terms of thermal time for four grapevine cultivars. Intl. J. Biometeorol. 59:1771-1781.

Zavalloni, C., J.A. Andresen, and J.A. Flore. 2006. Phenological models of flower bud stages and fruit growth of 'Montmorency' sour cherry based on growing degree-day accumulation. J. Amer. Soc. Hort. Sci. 131:601-607. 